\title{
ANÁLISE DAS RELAÇÕES CUSTO-VOLUME-LUCRO COMO INSTRUMENTO GERENCIAL: UM ESTUDO MULTICASO EM INDÚSTRIAS DE GRANDE PORTE DO RIO GRANDE DO SUL
}

\section{COST-VOLUME-PROFIT ANALYSIS AS MANAGEMENT TOOLS: A MULTI CASE STUDY IN LARGE INDUSTRIAL COMPANIES OF RIO GRANDE DO SUL STATE - BRAZIL}

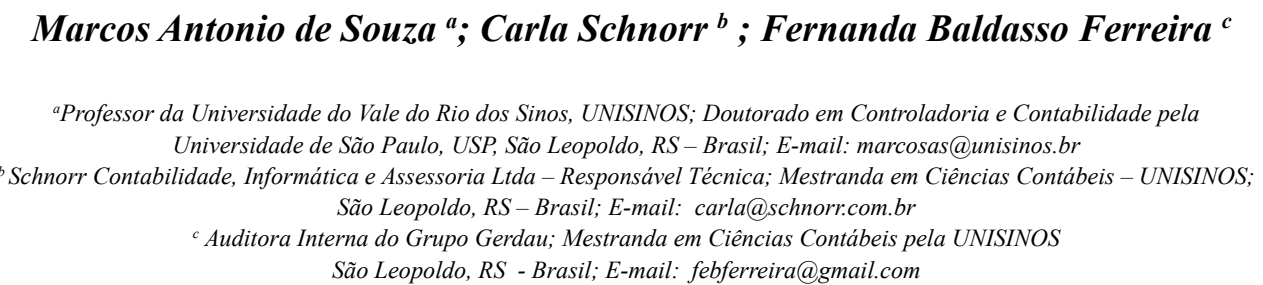

\section{Resumo}

O objetivo do artigo é investigar a utilização da análise custo-volume-lucro (CVL) no âmbito da gestão empresarial, considerando as técnicas de CVL mais diretamente relacionadas: margem de contribuição, ponto de equilíbrio, margem de segurança e alavancagem operacional. Trata-se de uma pesquisa descritiva e exploratória, com abordagem qualitativa. A metodologia adotada é o estudo de caso múltiplo, com coleta de dados baseada em entrevistas semi estruturadas realizada com três empresas de grande porte localizadas no estado do Rio Grande do Sul, pertencentes a diferentes segmentos da indústria: alimentício, químico e siderúrgico. Os principais resultados indicam que as técnicas da análise CVL não possuem aplicação prática tão expressiva quanto ao destaque que é dado pela literatura relacionada à contabilidade gerencial.

Palavras-chave: Análise C-V-L; Ponto de Equilíbrio; Margem de Segurança Operacional; Alavancagem Operacional.

\section{Abstract}

The study aims to investigate the utilization of cost-volume-profit (CVP) in the business administration including CVP related tools: margin of contribution, breakeven point, operational safety margin and operating leverage. It's a descriptive and exploratory study with qualitative approach. The methodology adopted is a multiple case study. Data were collected by application of semi structured interview with managers of three large companies of different industrial activity segments located in Rio Grande do Sul state: food, chemical and steel. The main results indicate that the CVP analysis practices have more importance in the literature about management accounting than the real application on the organizations.

Keywords: C-V-P Analysis; Breakeven Point;Operational Safety Margin; Operational Leverage. 


\section{INTRODUÇÃO}

As empresas, além de enfrentarem transformações ambientais externas, como a globalização, as instabilidades econômicas e a competitividade, precisam constantemente readequar as formas de conduzir as atividades internas em seu cotidiano, tais como a redução de custos, eliminação de desperdícios, aumento na qualidade dos produtos e no atendimento de clientes etc.

$\mathrm{Na}$ medida em que as variáveis existentes são modificadas, sejam elas de impacto externo (ameaças e oportunidades) ou interno (pontos fracos e pontos fortes), elas requerem a criação de instrumentos gerenciais que viabilizem conduzir os negócios com eficácia.

No âmbito da gestão empresarial, as práticas de contabilidade gerencial são desenvolvidas visando produzir informações precisas, confiáveis e que permitam aos gestores maior segurança e confiabilidade no gerenciamento da organização.

Nesse contexto de práticas de contabilidade gerencial, o estudo versa sobre a análise custo-volume-lucro (CVL), uma técnica de análise que permite examinar as inter-relações entre diversas variáveis, tais como: receitas, custos, despesas e volume de atividades, e a influência delas em relação ao lucro (HANSEN e MOWEN, 2001).

A importância da utilização da análise CVL é enfatizada pela literatura relacionada à contabilidade gerencial, sendo considerada como uma ferramenta de gestão que auxilia os processos de planejamento, gerenciamento e controle empresariais, podendo impactar de forma acentuada no processo decisório organizacional. Mesmo sendo caracterizada por uma ferramenta tradicional, pode-se constatar que a sua aplicação é pertinente no ambiente de negócios atual, seja no apoio a decisões rotineiras como em decisões estratégicas (MAHER, 2001).

Diante dessa realidade, o artigo tem como objetivo discutir a aplicação de tal técnica como uma ferramenta de gestão, uma forma de investigar o reconhecimento que a prática empresarial tem dado aos desenvolvimentos teóricos sobre o tema. A iniciativa desse estudo é referendada pelo entendimento dado por Iudícibus (1996), o qual destaca que o mais importante, na realidade, é a qualidade da prática contábil, acrescentando que a doutrina tem sua grande importância quando consegue projetar estruturas conceituais, mas devem ser validadas pelos experimentos reais.

Além disso, este estudo surge em complemento a diversos outros realizados sobre o tema, destacando-se Cheung e Heaney (1990), Souza, Lisboa e Rocha (2003), Yunker e Yunker (2003), Moraes e Wernke (2006), Yuan (2009), Busan e Dina (2009).

O artigo está estruturado em cinco seções. Esta primeira seção trata da introdução do trabalho, seguida da que trata dos aportes teóricos da pesquisa. A terceira seção apresenta os principais aspectos metodológicos adotados no desenvolvimento da pesquisa. Nas duas seções seguintes tem-se a apresentação e análise dos dados e as conclusões do estudo. Finaliza-se o conteúdo com a lista das referências utilizadas na pesquisa. 


\section{REFERENCIAL TEÓRICO}

\subsection{Sistema de informação contábil e práticas de gestão de custos}

Hansen e Mowen (2001) destacam que, nas últimas décadas. mudanças no ambiente de negócios têm afetado profundamente a contabilidade de custos e a gestão de custos nas empresas. Ainda conforme os autores, historicamente e independente das citadas mudanças, a gestão de custos está amparada nas informações da contabilidade de custos e do sistema de controle operacional.

Warren, Reeve e Fees (2001), com o mesmo enfoque, destacam que os principais subsistemas do sistema de informação contábil contemplam a contabilidade societária e a contabilidade gerencial, esta envolvendo também a de custos. Enquanto o primeiro subsistema se dedica a fornecer informações para os usuários externos, o segundo, gerencial, se preocupa com a forma de como as informações contábeis devem ser estruturadas e comunicadas para dar suporte ao processo decisório da organização, envolvendo as fases de planejamento, execução e controle das operações.

Detalhando um pouco mais tal entendimento, Atkinson et al (2008) enfatizam que é com as práticas de contabilidade gerencial que as empresas identificam, mensuram, informam e analisam as informações sobre os eventos econômicos da organização. Esse processo é principalmente orientado pelas necessidades interna de informações, pois não há órgãos ou legislações que regulem a contabilidade gerencial, dado que ela existe para suprir a administração de informações importantes para o alcance dos seus objetivos operacionais e estratégicos.

Frezatti, Guerreiro e Aguiar (2006) também se dedicaram a identificar alguns dos elementos que caracterizam o papel da contabilidade gerencial, destacando os seguintes:

(a) Composição do processo: as etapas que compõe o processo da contabilidade gerencial são assemelhadas, sendo elas: identificação, mensuração, acumulação, análise, preparação, interpretação e comunicação das informações.

(b) Informações para usuários: focadas exclusivamente aos usuários internos das organizações e em alguns casos destinadas apenas a gerência.

(c) Apoio ao processo decisório: suporte aos gestores com informações úteis que para a tomada de decisão.

(d) Conexão com os objetivos da entidade: tem como finalidade principal apoiar a administração na busca dos seus objetivos organizacionais.

Nesse sentido, é a gestão de custos, como um subsistema da contabilidade gerencial, que identifica, coleta, classifica e mensura as informações que são relevantes para os gestores a fim de auxiliá-los na tomada de decisões. Wernke (2004) acrescenta que em função das necessidades do usuário-alvo, é a gestão de cada organização que deve determinar, segundo suas razões, quando uma informação é relevante, qual a sua periodicidade e qual a forma de apresentação.

Maher (2001) destaca que é sob o prisma de um processo de gestão voltado a orientar o processo decisório que a gestão de custos destaca-se nos sistemas de gestão econômicos, 
financeiros e patrimoniais e engloba temas como métodos de custeio, estudo do preço de venda e análise CVL.

A respeito da utilidade da análise CVL destacada por Maher (2001) e Atkinson et al (2008) mencionam que diversas decisões gerenciais requerem a análise atenta do comportamento de custos e lucros em função das expectativas do volume de vendas. Por isso a importância da utilização das ferramentas de análise tipo CVL como apoio ao processo decisório, uma vez que ela aponta os efeitos das mudanças dos volumes de vendas na lucratividade da organização.

\subsection{A análise do custo, volume e lucro}

Ampliando a exposição inicial dada sobre a análise CVL, Maher (2001) destaca que ela é uma ferramenta que auxilia os gestores em seu processo decisório sobre o nível de operação dos negócios, no que tange a questões financeiras, econômicas e patrimoniais, podendo apontar para um impacto negativo nos resultados de uma possível retração ou expansão dos mesmos.

Para Warren, Reeve e Fees (2001), a análise CVL é um exame sistemático das relações entre preços de venda, volumes de produção e de venda, custos, despesas e lucros. É importante salientar, conforme salientado por Martins (2009), que a análise de alterações do custo, volume e lucro é utilizada tendo como base o método de custeio variável, visto que essa técnica necessita da segregação dos custos e despesas entre variáveis e fixos.

Busan e Dina (2009) e Horngren, Foster e Datar (2004) citam que como qualquer outro modelo matemático, a análise CVL precisa de certos pressupostos para dar validade aos seus resultados. As hipóteses básicas requeridas para uma correta estimação e compreensão do comportamento das variáveis envolvidas nessa análise são:

(a) Mudanças nas receitas e custos ocorrem devido a mudanças no número de unidades produzidas e vendidas.

(b) Os custos totais devem ser separados em custos fixos, os quais não variam conforme o nível de produção, e em custos variáveis, que variam de acordo com a produção.

(c) O preço de venda, os custos fixos e os variáveis são conhecidos e permanecem constantes dentro do período analisado.

(d) As receitas e os custos variáveis são lineares com relação à produção dentro de um período de análise.

(e) A análise cobre um único produto ou, quando da existência de múltiplos produtos, a proporção de venda desses produtos no todo se manterá constante quando da alteração da quantidade total de unidades vendidas.

(f) Todas as receitas e custos podem ser agregados e comparados sem levar em consideração o valor do dinheiro no tempo.

Estes pressupostos são importantes por dois aspectos: (a) para compreender os mecanismos que interferem no resultado do cálculo dos elementos que compõem a análise; (2) para entender que esta técnica não deve ser utilizada indiscriminadamente e de forma automática, sem que antes haja uma importante etapa de interpretação dos resultados.

A Figura 1 ilustra as ferramentas diretamente relacionadas à análise CVL e a relação 
entre elas. Considera-se importante, conforme destacado por Rayburn (1996), compreender que a análise se completa quando as ferramentas são utilizadas em conjunto, possibilitando uma visão mais completa do comportamento das relações custo-volume-lucro. A margem de contribuição, definida pela diferença entre o preço de venda e os custos e despesas variáveis é parte fundamental para a definição do ponto de equilíbrio. Este último possui relação direta com a margem de segurança, visto que tal margem é todo faturamento que ocorre acima daquele ponto. E a alavancagem operacional que estuda o efeito e comportamento dos custos fixos.

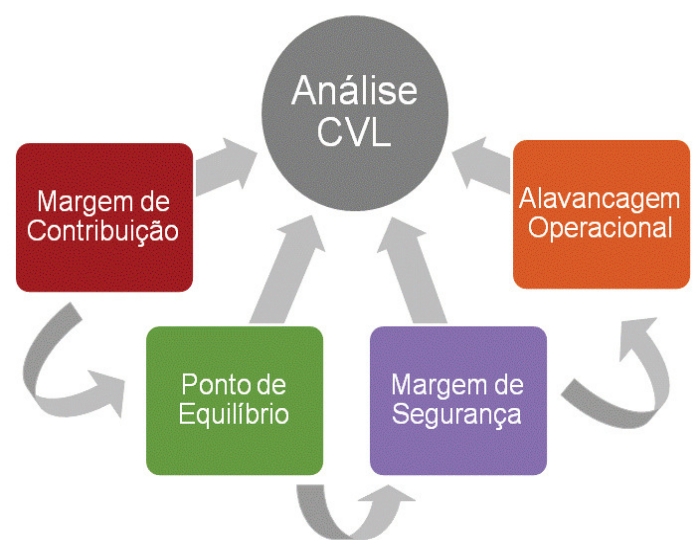

Figura 1: Análise CVL e Técnicas Relacionadas Fonte: Elaborado com base em Souza e Diehl (2009).

A literatura sobre gestão de custos, em geral, aborda o tema CVL dissertando sobre o ponto de equilíbrio, a margem de contribuição, a margem de segurança operacional e a alavancagem operacional. Os conceitos e características relacionados a esses elementos são tratados nas próximas seções.

\subsection{Margem de contribuição}

A expressão margem de contribuição designa o valor resultante da venda após serem deduzidos os custos e despesas variáveis associados ao produto comercializado. Essa margem, conforme Rayburn (1996) pode ser interpretada como a parte do preço de venda que ultrapassa os custos e despesas variáveis, e que contribuirá para cobertura dos custos fixos e ainda para geração do lucro. Assim, conforme atestam Souza e Diehl (2009) é possível inferir que quanto maior a margem de contribuição de um produto, mais ele contribui para formar o lucro, sendo ele, de maneira geral, preferencial na produção.

De acordo com Wernke (2004), a margem de contribuição pode ser calculada unitariamente ou no valor total, tanto em valor como em percentual. Martins (2009) acrescenta que quando for expressa em porcentagem ela é denominada índice de margem de contribuição e indica o efeito no lucro operacional originado pelo aumento ou diminuição no volume de vendas.

A margem de contribuição é um componente presente no cálculo das demais ferramentas da análise CVL, em virtude de estar diretamente relacionado com o PE e este com os demais conceitos de margem de segurança e de alavancagem operacional. É também considerada elemento chave em matéria de decisão quando há fator limitante de produção para atendimento 
da demanda de mercado. Nesses casos, conforme observado por Martins (2009), é importante analisá-la não na forma de valor unitário por produto, mas sim por fator limitante da capacidade produtiva, podendo ser ele expresso em horas-máquina, horas de mão-de-obra, quilos de matéria prima etc. Neste sentido, conforme ratificado por Souza e Diehl (2009), quando não existir limitação na capacidade produtiva, o produto mais rentável será o que apresentar maior margem de contribuição por unidade. De outra parte, quando existir algum fator limitante, o produto mais rentável será o que tiver maior margem de contribuição em relação ao fator limitante da capacidade produtiva. Entretanto, nesses casos, apesar do cálculo da margem de contribuição identificar qual produto deve ser priorizado, é importante salientar que a relação da empresa com seus clientes deve ser analisada, visto que sempre há uma relação de dependência entre ambos independente de limitações pontuais.

\subsection{Ponto de equilíbrio}

Uma das aplicações mais conhecidas e destacadas pela literatura da análise CVL é a determinação do ponto de equilíbrio das empresas. É por meio dessa ferramenta, conforme Rayburn (1996) que se pode definir o menor nível de operações no qual a organização não apresenta prejuízo, podendo ser expresso em termos de volume, de valores monetários e de percentual de utilização da capacidade produtiva.

Para Martins (2009, p. 257), “o ponto de equilíbrio, também chamado de ponto de ruptura, nasce da conjugação dos custos e despesas totais com as receitas totais". Warren, Reeve e Fees (2001) complementam que a receita que corresponde aos gastos totais é chamada de receita de equilíbrio e argumentam que, em consequência, qualquer nível de venda inferior a esse ponto significará perdas, ao mesmo tempo em que representa, inversamente, lucros, quando quaisquer níveis de vendas excederem o ponto identificado.

A técnica do ponto de equilíbrio divide-se em três modalidades: (1) ponto de equilíbrio contábil - PEC; (2) ponto de equilíbrio econômico - PEE; (3) ponto de equilíbrio financeiro PEF.

O PEC, de acordo com Dubois, Kulpa e Souza (2009), determina a quantidade mínima de produção e venda em que a empresa não obtém lucro, mas também não sofre prejuízos. É calculado, em unidades físicas ou em valor (\$), pela divisão dos custos e despesas fixas pela margem de contribuição.

PEE considera o retorno mínimo desejado pelos investidores e implica a cobertura dos custos totais acrescidos do lucro necessário para que o investimento seja adequadamente remunerado conforme o retorno desejado. A análise do PEE, conforme realça Atkinson et al (2008), também pode ser utilizada para identificação do lucro-meta ou lucro desejado. Com a inclusão do fator de retorno sobre investimento define-se a rentabilidade esperada pelos acionistas e verifica o volume de produção e venda necessários para o alcance da meta definida.

Por último tem-se o PEF, calculado quando a empresa deseja saber o volume de vendas suficiente para cobrir os custos e despesas variáveis, os custos e as despesas fixos desembolsáveis (exclui, por exemplo, a depreciação) e outras dívidas que a empresa tenha que saldar no período (WERNKE, 2004). Assim, conforme Souza e Diehl (2009), o PEF pode também ser utilizado nas situações em que o gestor precisa gerar um saldo mínimo de caixa. 
Representa então a quantidade de vendas necessárias para cobrir os custos desembolsáveis e gerar um saldo de caixa predeterminado, com o objetivo de saldar desembolsos futuros com reposição de imobilizado, novos investimentos, pagamento de dividendos ou outros tipos de obrigações que não são identificadas pelo resultado econômico.

Segundo Belkaoui (1987), os primeiros autores a sugerir o uso dos conceitos de probabilidade na análise CVL foram Jaedicke e Robichek (1964), uma vez que a análise tradicional não inclui ajuste para risco e incerteza, o que pode limitar sua utilidade, dado que a maioria das variáveis inclusas na fórmula do ponto de equilíbrio está sujeita a uma gama de possíveis resultados devido às chances de variações. Algumas destas variáveis são: o preço unitário de venda, o custo variável por unidade, o custo fixo total e o volume de vendas esperado para cada produto. Na seção de Simplificações da Análise CVL deste artigo, estas questões serão abordadas com mais detalhes.

Gitman (2004) concorda que o ponto de equilíbrio contábil de uma empresa é vulnerável a algumas variáveis. Por isso, demonstra que o volume de vendas no ponto de equilíbrio é afetado por determinadas variáveis, conforme apresenta o Quadro 1.

\begin{tabular}{|l|c|c|}
\hline \multicolumn{1}{|c|}{ Elementos da Análise } & Variação & Efeito no Ponto de Equilíbrio \\
\hline \multirow{2}{*}{ Custo ou Despesa Operacional Fixo } & Diminui & Diminui \\
\cline { 2 - 3 } & Aumenta & Aumenta \\
\hline \multirow{2}{*}{ Custo ou Despesa Operacional Variável Unitário } & Diminui & Diminui \\
\cline { 2 - 3 } & Aumenta & Aumenta \\
\hline \multirow{2}{*}{ Preço de Venda Unitário } & Diminui & Aumenta \\
\cline { 2 - 3 } & Aumenta & Diminui \\
\hline
\end{tabular}

Quadro 1: Variações e Efeitos no Ponto de Equilíbrio Fonte: Adaptado de Gitman (2004)

\subsection{Margem de segurança operacional}

A margem de segurança operacional (MSO) corresponde ao volume ou valor das vendas, planejadas ou realizadas acima do ponto de equilíbrio. Dubois, Kulpa e Souza (2009) enfatizam que essa margem indica a parte do faturamento que gera lucro da organização, além de demonstrar, também, o percentual das vendas que pode ser reduzido sem que a empresa tenha prejuízo.

A MSO, segundo Bruni e Famá (2008), trata de mensurar o nível de risco para o empreendimento. Para os autores, se determinada empresa calcular a quantidade de vendas e receitas e verificar que a mesma opera no nível do seu ponto de equilíbrio, deve ser considerada uma situação vulnerável, com falta de margem de segurança. Qualquer alteração desfavorável da demanda, por exemplo, pode levar a empresa a operar no prejuízo. Assim, conclui-se que quanto mais próxima a venda realizada estiver do ponto de equilíbrio, menor será a margem e maior será o risco operacional da ocorrência de prejuízo. Da mesma forma, a empresa que opera com o nível de vendas distante do ponto de equilíbrio, com margem de segurança elevada, está menos exposta a riscos.

Souza e Diehl (2009, p. 270) destacam que "um aspecto deve ser motivo de ressalva na determinação da Margem de Segurança: o percentual admissível de redução depende da receita atual, isto é, se a receita atual mudar, o percentual de redução admissível também irá mudar". 
De outra parte, a MSO positiva (venda real superior ao ponto de equilíbrio) passa a ser a faixa de faturamento geradora do lucro operacional, calculado pela multiplicação da MSO pela margem de contribuição.

\subsection{Alavancagem operacional}

A alavancagem operacional (AO) é definida por Garrison e Noreen (2001) como a medida do grau de sensibilidade do lucro às variações nas receitas de vendas, ou seja, sinaliza quantas vezes um acréscimo nas vendas refletirá sobre o lucro operacional da empresa e decorre da existência de custos fixos na estrutura de custos da empresa.

Segundo Gitman (2004), a AO é a possibilidade de uso dos custos operacionais fixos para ampliar os efeitos dos incrementos de vendas sobre o lucro bruto. Isso significa que uma ampliação das receitas de vendas resulta em uma mudança relativamente maior no resultado operacional, ou seja, busca-se a maximização do uso da capacidade instalada (estrutura fixa) da organização, representada pelos custos e despesas fixas.

Em resumo, a AO é uma referência utilizada para o gerenciamento dos custos fixos e representa a incerteza do lucro operacional em relação à incerteza das vendas. Destaca-se que a alavancagem operacional não leva em consideração as despesas financeiras, conforme demonstrado no Quadro 2 e dos conceitos apresentados por Dubois, Kulpa e Souza (2009).

\begin{tabular}{|c|c|c|}
\hline Vendas & \multirow{5}{*}{$\begin{array}{c}\text { Alavancagem } \\
\text { Operacional }\end{array}$} & \multirow{7}{*}{$\begin{array}{c}\text { Alavancagem } \\
\text { Combinada }\end{array}$} \\
\hline (-) Custo das vendas & & \\
\hline$(=)$ Lucro Bruto & & \\
\hline (-) Despesas Operacionais & & \\
\hline (=) Lucro Operacional & & \\
\hline (-) Despesas Financeiras & \multirow{2}{*}{$\begin{array}{c}\text { Alavancagem } \\
\text { Financeira }\end{array}$} & \\
\hline (=) Lucro Líquido & & \\
\hline
\end{tabular}

Quadro 2: Alavancagem Operacional, Financeira e Combinada

Fonte: Adaptado de Dubois, Kulpa e Souza (2009)

Observa-se que além da alavancagem operacional, a literatura também aborda outros dois tipos de alavancagem: a financeira e a combinada. Conforme Gitman (2004) a alavancagem financeira tem como base o aumento do lucro líquido, em contraponto às despesas financeiras, ou seja, é a capacidade da organização em maximizar a rentabilidade dos sócios em função da utilização de capitais de terceiros. A alavancagem combinada, por outro lado, pode ser definida como a capacidade da organização em usar custos fixos totais, operacionais e financeiros, para aumentar o efeito de variações nas vendas sobre o lucro.

Assim, segundo Garrison e Noreen (2001) o GAO pode ser definido como a variação percentual no lucro operacional em função de certa variação percentual nas quantidades vendidas. Este grau de alavancagem sinaliza quantas vezes um acréscimo nas vendas refletirá sobre o lucro operacional da organização.

Pela exposição do exemplo dado por Gitman (2004), conforme Figura 2, é possível verificar que um aumento nas vendas, de 1.000 para 1.500 unidades, resulta em um crescimento mais do que proporcional no lucro antes do imposto de renda, de $\$ 2.500$ para $\$ 5.000$. Neste ponto pode-se interpretar, aplicando a formula do Grau de Alavancagem Operacional (variação percentual do lucro / variação percentual das vendas), que há um GAO de 2 . Ou seja, é possível alavancar os lucros da empresa em 2 vezes mais que o aumento da quantidade de vendas realizada, 
em função da melhor utilização dos custos fixos. Adicionalmente, a Figura 2 demonstra as áreas de margem de segurança operacional positiva e negativa, o ponto de equilíbrio e os pontos de GAO de maior e de menor impacto.

Assim, Pode-se inferir que quanto mais próximo o nível de vendas estiver do ponto de equilíbrio, maior será a alavancagem operacional, pois é maior o potencial de utilização da capacidade de produção para incrementar as vendas. E quanto mais longe estiver do ponto de equilíbrio, menos disponibilidade de utilização dos custos fixos terá para incrementar suas vendas, sem realizar aumento nesses custos (novos investimentos), sendo assim menor o seu grau de alavancagem (GITMAN, 2004).

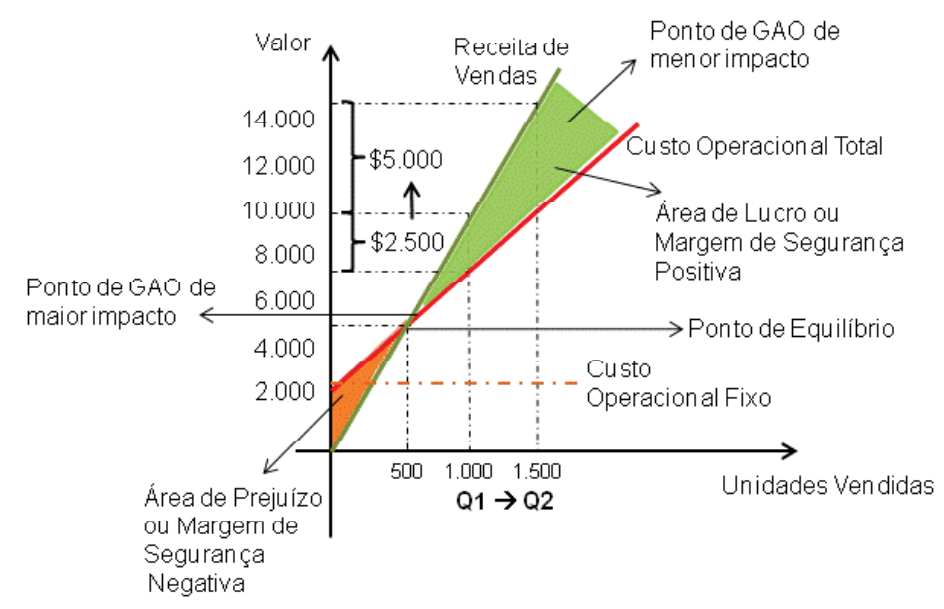

Figura 2: Alavancagem Operacional, Ponto de Equilíbrio e Margem de Segurança.

Fonte: Adaptado de Gitman (2004)

A respeito dos reflexos de alterações das variáveis consideradas no estudo da MSO, Martins (2009) acrescenta que a cada $1 \%$ de alteração nos custos e despesas fixos, ocorre a mesma variação de $1 \%$ no ponto de equilíbrio; mas se a mudança for sobre os custos e despesas variáveis ou sobre o preço de venda, o efeito dependerá do grau de alteração na margem de contribuição.

Além disso, como ilustrado na Figura 2, o GAO é inversamente proporcional à margem de segurança operacional. Quanto mais próximo do ponto de equilíbrio maior é a GAO e menor é a margem de segurança operacional. Sendo o inverso também verdadeiro.

Como destaca Gitman (2004), é possível explicar, também, que quanto mais próximo o nível de atividade estiver do ponto de equilíbrio, menor é o lucro e maior é o grau de alavancagem. Nesse nível constata-se que a empresa está exposta a um maior risco operacional, estando mais vulnerável a alterações de demanda e custos. Em contrapartida, quanto mais distante do ponto equilíbrio estiver o nível de atividades maior é o lucro, o que torna mais difícil o seu aumento com a mesma estrutura de custos fixos. Identifica-se, neste caso, um grau de alavancagem menor.

\subsection{Aplicações da análise}

Parcela significativa da literatura consultada faz as mesmas referências quanto às 
aplicabilidades da análise CVL. Os autores abordam que a análise é uma ferramenta de gestão que auxilia o planejamento e controle dos processos, e, principalmente, apóia a tomada de decisão de curto prazo. É o que está descrito no Quadro 3.

De acordo com Souza e Diehl (2009), a análise CVL também é base para decisões do tipo comprar versus fazer, igualmente chamada de externalização ou terceirização. Esse tipo de avaliação ocorre quando uma organização encontra-se em dúvida se é mais vantajoso comprar determinado produto ou serviço no mercado ou produzi-lo internamente.

A respeito desse tipo de decisão, Andrioli (2009) cita que existem variáveis que devem ser consideradas em situações de decisão de fazer versus comprar, tais como: (a) comparação entre os custos de fabricar e os de comprar; (b) grau de ocupação da fábrica antes de ser tomada a decisão; (c) problemas do mercado demandante; (d) tempo de espera no mercado ofertante; (e) obter acesso a capacidades de nível mundial; (f) acelerar os benefícios de reengenharia; (g) qualidade dos componentes; (h) segurança da decisão no longo prazo.

\begin{tabular}{|l|l|}
\hline \multicolumn{1}{|c|}{ Obras } & \multicolumn{1}{c|}{ Aplicações da Análise CVL } \\
\hline \multirow{4}{*}{ Wernke (2004) } & à introdução de novas linhas de produto; \\
\cline { 2 - 3 } & à projeção de lucros; \\
\cline { 2 - 3 } à definição de preços de transferência; \\
\hline \multirow{4}{*}{ Souza e Diehl (2009) } & à determinação de preços de venda; \\
\cline { 2 - 3 } & à programação de volumes produtivos; \\
\cline { 2 - 3 } & à remuneração variável; \\
\cline { 2 - 3 } & à estimativa de custos futuros; \\
\cline { 2 - 3 } & à redução de custos, despesas e gastos; \\
\hline \multirow{4}{*}{ Warren, Reeve e Fees (2001) } & a escolher melhores estratégias de marketing; \\
\cline { 2 - 3 } & a selecionar o mix de produtos para produção e vendas; \\
\cline { 2 - 3 } & a analisar os efeitos dos custos sobre os lucros; \\
\cline { 2 - 3 } & ao dimensionamento da capacidade produtiva; \\
\hline \multirow{2}{*}{ Dubois, Kulpa e Souza (2009) } & à elaboração de orçamentos; \\
\cline { 2 - 3 } & à identificação da viabilidade econômica de projetos. \\
\hline
\end{tabular}

Quadro 3: Aplicabilidades da Análise CVL

Dalmonech et al (2003) destaca, no entanto, que embora a análise CVL seja uma ferramenta útil no processo de planejamento e controle, o modelo está estruturado a partir de hipóteses simplificadoras e que limitam a sua aplicabilidade, ou seja, presume a existência de determinadas condições hipotéticas que muitas vezes não se materializam na prática. Esse é o conteúdo abordado na próxima seção.

\subsection{Simplificações e características da análise CVL}

Assim como outras técnicas e ferramentas gerenciais, a análise CVL possui algumas simplificações na sua construção e uso, as quais podem interferir nos resultados finais. Essas simplificações exigem dos administradores e usuários uma análise mais criteriosa no momento da interpretação dos seus resultados.

Uma dessas simplificações decorre da classificação dos custos em fixos e variáveis. Embora essa classificação possa ser mais fácil para algumas empresas, para outras isso pode ser de maior dificuldade (SOUZA e DIEHL, 2009).

Além disso, há que se reconhecer que a análise CVL reflete um resultado útil em curto prazo, pois considera os custos fixos e variáveis, os processos de produção e o mix de vendas 
constantes para a realização do cálculo. Como é sabido, o mercado é afetado por instabilidades das demandas, dos preços de venda de produtos e dos preços de compra de matérias-prima e de outros custos, provocando a partir disso a dificuldade em se analisar um cenário por um longo período utilizando-se de um método que considera estes elementos constantes. Sendo assim, é importante que os resultados identificados sejam considerados como válidos para uma dimensão temporal de curto prazo, levando em consideração as características do mercado e dos produtos em estudo (RAYBURN, 1996; GUIDRY, HORRIGAN e CRAYCRAFT, 1998).

Outro aspecto a ser observado é que a análise CVL não considera a atualização do dinheiro com o passar do tempo, principalmente os efeitos da inflação na desvalorização da moeda. Conforme destacam Souza e Diehl (2009), os menores níveis inflacionários atualmente presentes na economia brasileira, quando comparativamente analisados em relação ao histórico de instabilidade econômica nacional, não devem ser desprezados em um estudo mais criterioso.

Também deve ser destacada a simplificação adotada na relação entre o volume produzido e o volume vendido. Quando da realização e interpretação dos resultados, tem-se como pressuposto que o volume produzido pela empresa será igual à quantidade de produtos vendidos, o que pode não ocorrer na prática.

Outro fator importante a considerar é que, no momento da análise e decisão por aumento de produção ou diferenciação no mix dos produtos, à estrutura de ativos atual um novo investimento deve ser incluído. Considerando que estas mudanças podem refletir em um aumento dos custos fixos da organização, a nova estrutura dos fatores de produção e demais ativos devem fazer parte da análise para tomada de decisão. Ao tratar dessa questão, Guirdy, Horrigan e Graycraft (1998) destacam que quando da inclusão à estrutura de ativos na análise, é necessário considerar que as decisões que envolvem mudanças na estrutura de ativos e de custos fixos podem gerar uma variação no risco operacional que a empresa está exposta. $\mathrm{O}$ aumento destes custos torna a empresa menos ágil e menos flexível para se adaptar às mudanças, tornando-a mais exposta a variações da demanda e de preços. Assim, a decisão para aumento dos fatores de produção, baseada na análise CVL, precisa ser tomada com o conhecimento de que haverá um aumento do risco operacional até então considerado.

Dalmonech et al (2003) abordam outras simplificações da análise CVL tradicional, destacando as seguintes:

(a) Suposição de perda zero durante o processo produtivo, ou seja, todo o volume produzido é vendido.

(b) Considera que a estrutura do capital é $100 \%$ própria, não havendo pagamento de juros ou despesas financeiras sobre empréstimos.

(c) Suposição de receita única, referente aos produtos que estão sendo estudados na análise. Não considera, por exemplo, receitas provenientes de aplicações financeiras ou de receitas sobre vendas de resíduos ou subprodutos.

Apesar das simplificações do modelo, citadas anteriormente, Rayburn (1996) comenta que elas não invalidam o modelo, mas requerem uma interpretação mais cuidadosa dos resultados. Além disso, cita que a análise CVL é considerada como um recurso importante para suportar a tomada de decisões operacionais nas empresas. Souza e Diehl (2009) complementam esclarecendo que pequenas distorções provocadas por tais simplificações e características, se bem trabalhadas, não alteram substancialmente o resultado do uso desse tipo de análise, nem 
eliminam os seus atributos principais, mas que devem ser observadas quando do seu uso.

\subsection{Estudos relacionados}

Com base nas pesquisas realizadas sobre contabilidade gerencial e custos foi identificado um expressivo destaque na literatura, particularmente em livros, para a análise CVL e suas principais práticas.

Entretanto, com base em pesquisa realizada nos artigos científicos publicados no Congresso de Controladoria e Contabilidade da USP (2010), do Congresso Brasileiro de Custos (2010) e dos Encontros da ANPAD (2010) não se observa a mesma incidência de estudos sobre o tema. Foi analisado um período de 10 anos para cada um desses eventos, de cujos anais selecionaram-se os artigos relacionados às áreas de controladoria e contabilidade gerencial. Seguem alguns detalhes importantes sobre a pesquisa realizada:

(a) Para os Encontros da ANPAD e para o Congresso Brasileiro de Custos os 10 anos pesquisados se referem ao período de 2000 a 2009, visto que os trabalhos do ano de 2010 ainda não haviam sido publicados até a data de encerramento deste estudo.

(b) Para o Congresso da USP analisou-se o período de 2001 a 2010.

(c) A análise dos trabalhos aprovados foi realizada através da leitura dos seus respectivos resumos.

Constam da Tabela 1 os resultados das pesquisas realizadas sobre as bases de dados dos três congressos citados.

\begin{tabular}{|c|c|c|c|c|c|c|c|c|c|c|c|c|c|c|c|c|c|c|c|c|c|c|c|c|c|}
\hline \multirow{3}{*}{ Congressos } & \multicolumn{22}{|c|}{ Períodos analisados } & \multirow{2}{*}{\multicolumn{3}{|c|}{ Período de 10 anos }} \\
\hline & \multicolumn{2}{|c|}{2010} & \multicolumn{2}{|c|}{2009} & \multicolumn{2}{|c|}{2008} & \multicolumn{2}{|c|}{2007} & \multicolumn{2}{|c|}{2006} & \multicolumn{2}{|c|}{2005} & \multicolumn{2}{|c|}{2004} & \multicolumn{2}{|c|}{2003} & \multicolumn{2}{|c|}{2002} & \multicolumn{2}{|c|}{2001} & \multicolumn{2}{|c|}{2000} & & & \\
\hline & Total & CVL & Total & $\mathrm{CVL}$ & Total & $\mathrm{cVI}$ & Total & CVL & Total & CVL & Total & $\mathrm{cVI}$ & Total & CVL & Total & $\mathrm{CVI}$ & Total & cVI & & $\mathrm{CVL}$ & Total & $\mathrm{CVL}$ & Total & $\mathrm{CVL}$ & $\%$ \\
\hline EnANPAD & & - & 18 & 0 & 26 & 0 & 38 & 1 & 32 & 1 & 31 & 0 & 68 & 0 & 55 & 0 & 46 & 0 & 23 & 0 & 21 & 1 & 358 & 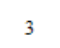 & 0,8 \\
\hline Congresso USP & 101 & 0 & 68 & 0 & 84 & 0 & 120 & 0 & 150 & 0 & 100 & 0 & 100 & 1 & 100 & 1 & 85 & 0 & 74 & 0 & & - & 982 & 2 & 0,2 \\
\hline $\begin{array}{l}\text { Brasileiro de } \\
\text { Custos }\end{array}$ & - & - & 253 & 2 & 267 & 4 & 238 & 2 & 212 & 1 & 350 & 4 & 244 & 3 & 140 & 3 & 200 & 4 & 134 & 1 & 139 & 0 & 2.177 & 24 & 1,1 \\
\hline Total: & 101 & 0 & 339 & 2 & 377 & 4 & 396 & 3 & 394 & 2 & 481 & 4 & 412 & 4 & 295 & 4 & 331 & 4 & 231 & 1 & 160 & 1 & 3.517 & 29 & 0,8 \\
\hline
\end{tabular}

Tabela 1: Análise dos trabalhos aprovados nos congressos nacionais Fonte: ANPAD (2010), USP (2010) e ABC (2010).

Ao analisar a quantidade de trabalhos desenvolvidos sobre a análise CVL nos congressos, é possível identificar a baixa expressividade do assunto. No período de 10 anos foram identificados 29 trabalhos sobre o tema, correspondente a apenas $0,8 \%$ do total de artigos aprovados.

Tendo em vista esta baixa incidência de trabalhos sobre CVL, torna-se difícil mensurar uma possível queda ou aumento do número sobre o total publicado, visto que desde 2002 o número varia de 2 a 4 trabalhos por ano. Considerando que os congressos têm como objetivo promover o debate de idéias novas sobre a teoria e a prática, pode-se afirmar que o estudo sobre as relações do custo-volume-lucro não tem presença relevante na agenda dos pesquisadores 
como tema para potenciais estudos, apesar da destacada relevância dada nos livros que abordam as práticas de contabilidade gerencial. No Quadro 4 estão apresentados os 29 trabalhos identificados sobre a análise CVL.

\begin{tabular}{|c|c|c|c|c|}
\hline \# & Ano & Congresso & Título & bjetivo do Estudo \\
\hline 1 & 2000 & רANPAD & $\begin{array}{c}\text { Relação entre o Risco Sistemático da Empresa e o Grau de } \\
\text { Alavancagem Operacional: Análise do Setor Siderúrgico } \\
\text { Brasileiro }\end{array}$ & $\begin{array}{l}\text { Análise sobre a estrutura de custos fixos versus } \\
\text { o risco operacional ao qual a empresa se expõe }\end{array}$ \\
\hline 2 & 2001 & $\begin{array}{l}\text { CBC } \\
\text { Congresso } \\
\text { Brasileiro } \\
\text { de Custos }\end{array}$ & $\begin{array}{l}\text { Aplicação da relação de custo-volume-lucro associada à lei } \\
\text { dos rendimentos decrescentes para análise da produção mais } \\
\text { lucrativa para postos de trabalho industriais onde o custo de } \\
\text { mão-de-obra é determinante. }\end{array}$ & $\begin{array}{l}\text { Demonstrar como uma alteração na composição } \\
\text { dos custos fixos ou dos custos variáveis, pode } \\
\text { alterar o comportamento econômico da empresa }\end{array}$ \\
\hline 3 & 2002 & $\mathrm{CBC}$ & $\begin{array}{c}\text { Análise de Custo/volume/lucro: Estudo de Caso Em Pequena } \\
\text { Empresa de Facção }\end{array}$ & \\
\hline 4 & 2002 & $\mathrm{CBC}$ & $\begin{array}{l}\text { Análise Custo/volume/lucro Aplicada Na Suinocultura: Estudo } \\
\text { de Caso Em Pequena Propriedade Catarinense }\end{array}$ & $\begin{array}{l}\text { Utilização das ferramentas da análise CVL em } \\
\text { uma empresa de criação de suínos. }\end{array}$ \\
\hline 5 & 2002 & $\mathrm{CBC}$ & $\begin{array}{l}\text { Análise da Relação Custo/volume/lucro Aplic } \\
\text { Pequena Instituição de Ensino Superior Per }\end{array}$ & \\
\hline 6 & 2002 & $\mathrm{CBC}$ & $\begin{array}{l}\text { Análise do Ponto de Equilíbrio dos Custos Financeiros Para } \\
\text { Investimento Em Inovações }\end{array}$ & $\begin{array}{l}\text { Ponto de equilíbrio fi } \\
\text { caixa mínimo capaz }\end{array}$ \\
\hline 7 & 2003 & $\mathrm{CBC}$ & $\begin{array}{l}\text { Custo-Volume-Lucro como Ferramenta de Gestão em uma } \\
\text { Empresa Prestadora de Serviços }\end{array}$ & $\begin{array}{l}\text { Utilização de pla } \\
\text { CVL em un }\end{array}$ \\
\hline 8 & 2003 & $\mathrm{CBC}$ & $\begin{array}{l}\text { Análise das Relações de Custo-Volume-Lucro, um Instrumento } \\
\text { de Gestão }\end{array}$ & $\begin{array}{r}\text { Conceitos da A } \\
\text { custeio }\end{array}$ \\
\hline 9 & 2003 & $\mathrm{CBC}$ & $\begin{array}{r}\text { Limitações da Análise Tradicional de Custo-Vo } \\
\text { Repensando as Hipóteses Simplificadoras d }\end{array}$ & $\begin{array}{l}\text { Análise CVL } \\
\text { regressão e }\end{array}$ \\
\hline 10 & 2003 & $\begin{array}{l}\text { Congresso } \\
\text { USP }\end{array}$ & $\begin{array}{l}\text { Instituições Filantrópicas Hos } \\
\text { ponto de equilíbrio entre isençõ }\end{array}$ & \\
\hline 11 & 2004 & $\mathrm{CBC}$ & $\begin{array}{r}\text { Análise das relações custo- } \\
\text { matemáticos para calcula } \\
\text { alterações em em }\end{array}$ & $\begin{array}{r}\text { Apresentar téc } \\
\text { possibilitam c } \\
\text { empresas f }\end{array}$ \\
\hline 12 & 004 & $\mathrm{CBC}$ & $\begin{array}{r}\text { Análise custo/v } \\
\text { estudo }\end{array}$ & $\begin{array}{r}\text { Aplicação da aná } \\
\text { su }\end{array}$ \\
\hline 13 & 2004 & $\mathrm{CBC}$ & $\begin{array}{r}\text { Custos releval } \\
\text { têxtil do }\end{array}$ & $\begin{array}{l}\text { Identificar as deci } \\
\text { base em custos e a }\end{array}$ \\
\hline 14 & 2004 & $\begin{array}{l}\text { Congresso } \\
\text { USP }\end{array}$ & $\begin{array}{c}\text { Análise da Variação da Margem de Contribuição Unitária } \\
\text { na Indústria Moageira do Trigo a partir do Preço do Trigo } \\
\text { em Grão, da Cotação do Dólar e do Volume Negociado: Um } \\
\text { Estudo de Caso }\end{array}$ & $\begin{array}{r}\text { Investigar o impacto na } 1 \\
\text { das variações do pre } \\
\text { argentino e da cotac }\end{array}$ \\
\hline 15 & 2005 & $\mathrm{CBC}$ & $\begin{array}{r}\text { Análise custo/volume/lucro ap } \\
\text { den }\end{array}$ & $\begin{array}{ll}\text { o e } \\
\text { esa }\end{array}$ \\
\hline 16 & 05 & $\mathrm{C}$ & álice custo/volume/lucro a & Aplicar a anális \\
\hline 17 & 05 & $\mathrm{BC}$ & usto/volume/lucro: fator decisivo na análise de investimento & Viabilidade de investimento em uma franquia \\
\hline 18 & 05 & $\mathrm{BC}$ & $\begin{array}{l}\text { Ponto de equilíbrio tributário (breal } \\
\text { pessoas jurídicas tributadas pelo lu }\end{array}$ & $\begin{array}{r}\text { Aplicar o I } \\
\text { tributação q }\end{array}$ \\
\hline 19 & 2006 & $\mathrm{CBC}$ & $\begin{array}{r}\text { Análise Custo/Volu } \\
\text { caso }\end{array}$ & $\begin{array}{r}\text { Aplicaçã } \\
\text { de }\end{array}$ \\
\hline 20 & 2006 & EnANPAD & $\begin{array}{l}\text { Utilização de } \mathrm{N} \\
\text { Custo-Volume- } \\
\text { em um }\end{array}$ & $\begin{array}{l}\text { Complementar a Análise CVL com o uso do } \\
\text { modelo de Simulação de Monte Carlo e com a } \\
\text { análise de regressão. }\end{array}$ \\
\hline 21 & 2007 & $\mathrm{CBC}$ & $\begin{array}{l}\text { O Ponto de Equilibri } \\
\text { Decisão Estratégica na G }\end{array}$ & $\begin{array}{l}\text { Aplicar o PE contábil, financeiro e econômico } \\
\text { para auxiliar na gestão de custos. }\end{array}$ \\
\hline 22 & 07 & BC & $\begin{array}{r}\text { Acompanhamento diări } \\
\text { ferramenta informatizada } \\
\text { micro e pequenas }\end{array}$ & $\begin{array}{l}\text { Criar planilha em MS-Excel para melhorar } \\
\text { a acurácia da análise CVL nas MPE’s } \\
\text { multiprodutoras. }\end{array}$ \\
\hline 23 & 2007 & EnANPAD & $\begin{array}{l}\text { Alavancag } \\
\text { do Recurso }\end{array}$ & $\begin{array}{l}\text { Aplicabilidade da m } \\
\text { empresa com restriç }\end{array}$ \\
\hline 24 & 08 & BC & $\begin{array}{l}\text { Ferramenta de Simulação da Margem de Contribuição no } \\
\text { Desenvolvimento de Novos Produtos: Estudo de Caso em } \\
\text { Indústria de Biscoitos }\end{array}$ & $\begin{array}{l}\text { Aplicar a análise CVL como suporte para } \\
\text { tomada de decisões sobre custos }\end{array}$ \\
\hline 25 & 08 & $3 \mathrm{C}$ & $\begin{array}{r}\text { Controle de custos: ferr } \\
\text { Peque }\end{array}$ & $\begin{array}{l}\text { Aplicar a análise CVL como suporte para a } \\
\text { gestão de custos }\end{array}$ \\
\hline 26 & 08 & $3 \mathrm{C}$ & $\begin{array}{r}\text { A utilização dos indicad } \\
\text { de alavancagem opera } \\
\text { resultados de } n\end{array}$ & $\begin{array}{c}\text { Cálculo da margem de contribuição e } \\
\text { alavancagem operacional nas filiais de uma rede } \\
\text { varejista. }\end{array}$ \\
\hline 27 & 8 & $\mathrm{CBC}$ & $\begin{array}{l}\text { Determinação da margen } \\
\text { variabilidade de pre }\end{array}$ & $\begin{array}{l}\text { Analisar a utilização da margem de contribuição } \\
\text { com a simulação de Monte Carlo }\end{array}$ \\
\hline 28 & 2009 & $\mathrm{CBC}$ & $\begin{array}{c}\text { Ampliação do Ponto de Equilíbrio para tomada de decisão em } \\
\text { qualquer horizonte de planejamento. }\end{array}$ & $\begin{array}{c}\text { Identificar os benefícios do Ponto de equilíbrio } \\
\text { e suas limitações }\end{array}$ \\
\hline 29 & 2009 & $\mathrm{CBC}$ & $\begin{array}{l}\text { Aplicação gerencial da margem de contribuição em uma } \\
\text { indústria de extração e beneficiamento de minérios }\end{array}$ & $\begin{array}{l}\text { Utilização da margem de contribuição como } \\
\text { suporte ao processo decisório da empresa }\end{array}$ \\
\hline
\end{tabular}

Quadro 4: Artigos publicados em congressos nacionais sobre Análise CVL

Fonte: ANPAD (2010), Universidade de São Paulo (2010) e ABC (2010).

Ao analisar os trabalhos sobre a análise CVL, é possível constatar que mais de $80 \%$ 
(equivalente a 24 artigos) dos estudos encontrados sobre o tema foram divulgados pelo Congresso Brasileiro de Custos. Desses 24 artigos, 12 são relacionados à aplicação da análise em micro e pequenas empresas e cinco sem aplicação prática, restritos a revisão bibliográfica. Os cinco artigos divulgados pelas edições dos Congressos da USP e na EnANPAD possuem conteúdos mais complexos, incluindo outros conceitos ao estudo da análise CVL, tais como a relação entre risco operacional e grau de alavancagem operacional nas empresas do setor siderúrgico brasileiro.

Como complemento às análises realizadas nos anais dos Congressos identificou-se alguns estudos sobre a aplicabilidade da análise CVL nas organizações. Cita-se a pesquisa realizada por Souza, Lisboa e Rocha (2003) com o objetivo de identificar as práticas de contabilidade gerencial utilizadas por 49 subsidiárias brasileiras de empresas multinacionais. Dentre as práticas pesquisadas, os autores incluíram a análise das relações custo-volume-lucro, com foco sobre o uso do ponto de equilíbrio e da margem de contribuição. Os dados coletados confirmam que a aplicação rotineira do ponto de equilíbrio não é realidade nas organizações, dado que somente $49 \%$ das empresas declararam utilização eventual e em 39\% não há nenhuma utilização. Com relação à margem de contribuição, foi possível constatar que $49 \%$ utilizam eventualmente e $20 \%$ não utilizam, ou seja, quase $70 \%$ do total das empresas pesquisadas não referendam a utilidade que é tão citada e destacada na literatura.

Cita-se, também, o estudo de Moraes e Wernke (2006) os quais aplicam cada um dos conceitos relacionados à análise CVL em uma empresa de médio porte do estado de Santa Catarina, que captura e comercializa pescados para o mercado interno e para exportação. Após a aplicação das técnicas da análise CVL, os gestores da empresa identificaram informações antes não existentes para a tomada de decisão, sendo elas: margem de contribuição por produto e total, ponto de equilíbrio em unidades e por faturamento, margem de segurança e a projeção de resultados futuros. Mesmo com as limitações da ferramenta, identificadas no artigo, foi concluído que a análise CVL pode contribuir de forma relevante no processo de tomada de decisão.

Além dessa pesquisa em congressos brasileiros, outra foi feita em periódicos internacionais. Nessa segunda etapa foram também identificados estudos sobre a análise CVL, porém, com um foco específico sobre formas de cálculo do ponto de equilíbrio, incluindo variáveis probabilísticas ou funções econômicas. A seguir são citados alguns dos artigos identificados.

O estudo realizado por Yunker e Yunker (2003) faz referência à necessidade de utilização da análise CVL levando em consideração a incerteza de algumas variáveis. Os autores consideram a inclusão da função econômica da oferta e demanda, relacionando o preço de venda com a quantidade de oferta. O preço de venda não é mais controlado e não possui um valor fixo, mas passa a ser tratado como variável, dependendo dos cenários definidos pelo analista.

Yuan (2009) também traz uma nova forma de análise CVL, a qual não ignora o risco e as incertezas de uma operação. Propõe um modelo que emprega o conceito da lógica fuzzy. Essa variável trabalha com diferentes probabilidades sobre cada fator do cálculo do ponto de equilíbrio. Esse modelo utiliza um sistema computacional probabilístico que auxilia os gestores a acessar e avaliar o impacto da gestão custo-volume-lucro, mediante diversas variáveis, e tomar a melhor decisão com base em diferentes cenários simulados.

O estudo realizado por Cheung e Heaney (1990) propõe a inclusão do orçamento 
de capital no cálculo da análise CVL. Esse orçamento parte de uma análise realizada pelas empresas para um planejamento em ativos de longo prazo ou de investimentos de capital. Além de impactar na flexibilidade da organização frente às mudanças do mercado, o montante de fundos comprometidos é muito elevado podendo gerar riscos financeiros. Neste estudo é proposta uma fórmula de cálculo que inclui a probabilidade de materialização dos riscos ao qual a empresa está exposta, dependendo do seu orçamento de capital.

\section{ASPECTOS METODOLÓGICOS}

O presente estudo caracteriza-se por ter uma abordagem qualitativa quanto ao tratamento do problema de pesquisa. Segundo Saha e Corley (2006, p. 1824) "os principais benefícios do método qualitativo são: possibilidade dos pesquisadores descobrirem novas variáveis e relações, revelar e entender processos mais complexos e conseguir ilustrar a influencia do contexto social nas pesquisas"

Quanto aos objetivos é considerada de caráter descritivo e exploratório. Sustentando essa classificação, Gil (1999) comenta que a pesquisa descritiva visa descrever as características de determinada população ou fenômeno, ou o estabelecimento de relações entre variáveis. Complementando sua classificação geral, a pesquisa é exploratória, a qual tem o objetivo de proporcionar maior familiaridade com o objeto de estudo, tentando torná-lo explícito ou a construir hipóteses.

O estudo foi desenvolvido sob o formato de estudo de casos múltiplos, selecionandose três indústrias brasileiras, localizadas no estado do Rio Grande do Sul, para a realização da coleta de dados. As empresas selecionadas são consideradas de grande porte, de acordo com a classificação definida pelo BNDES (2010) e de atuação em segmentos distintos, conforme apresentado no Quadro 5. O propósito da análise do estudo em diferentes setores é explorar a possibilidade de identificar utilização diferenciada entre empresas de segmentos distintos.

Segundo Ventura (2007) os estudos de caso podem focar em uma unidade ou um indivíduo (caso único e singular) ou múltiplo, nos quais vários estudos são conduzidos simultaneamente.

\begin{tabular}{|c|c|c|}
\hline Empresa & Segmentos de Atuação & Porte conforme BNDES (2010) \\
\hline 1 & Alimentício & Médio-Grande porte \\
\hline 2 & Químico & Grande porte \\
\hline 3 & Siderúrgico & Grande porte \\
\hline
\end{tabular}

Quadro 5: Detalhe sobre as empresas selecionadas

Fonte: Dados da Pesquisa

Para Eisenhardt (1989), os estudos de casos, sejam eles simples ou múltiplos, são focados no entendimento da dinâmica presente em um cenário ou ambiente. É uma pesquisa estratégica que pretende descrever uma realidade que pode ser replicada logicamente em outros cenários similares.

Como forma de manter o rigor da pesquisa cientifica, foi realizado um protocolo de estudo de caso a fim de formalizar a estruturação da pesquisa. O protocolo definido estabelece questões importantes para a pesquisa, conforme citado por Yin (2001), sendo eles: (a) visão geral do projeto contendo os objetivos, questões básicas e o referencial teórico que suportará o estudo; (b) procedimentos de campo, para a realização das entrevistas, incluindo revisão das 
informações prévias, documentos importantes a serem analisados, relação dos entrevistados e o roteiro da entrevista; (c) plano de análise para cada estudo e um esboço do relatório individual e (d) plano de análise para análise conjunta dos casos e conclusão sobre os resultados encontrados.

Para cada caso selecionado, a coleta de dados foi desenvolvida via entrevista realizada com o responsável pela área de custos em cada uma das empresas. Utilizou-se de um roteiro com perguntas abertas semiestruturadas, a fim de permitir flexibilidade nas respostas. De acordo com Lakatos e Marconi (1999), este tipo de entrevista é considerado como uma técnica em que o entrevistador segue um roteiro previamente estabelecido e, caso haja necessidade durante o desenvolvimento, possui a liberdade de incluir novas questões para atingir o objetivo. Além das entrevistas, foram realizadas pesquisas documentais para entendimento das atividades das empresas, principalmente de relatórios gerenciais de custos.

A análise dos dados foi realizada em duas etapas, sendo a primeira uma análise individual, também chamada de within-case analysis, na qual se realizou um estudo de cada caso com o objetivo entender a realidade das empresas e concluir sobre o porquê da utilização ou não da análise CVL. Na segunda etapa se comparou os três casos entre si, com a técnica cross-case analysis, buscando similaridades e diferenças entre eles que facilitem a obtenção de conclusões gerais a respeito do objeto em estudo (YIN, 2001; NETO, FENSTERSEIFER e FORMOSO, 2003).

\section{APRESENTAÇÃO E ANÁLISE DOS DADOS}

Esta seção contém a descrição e análise dos dados coletados durante a realização da pesquisa de campo. Inicialmente, apresenta-se um breve perfil das empresas selecionadas, a fim de fornecer uma visão geral sobre sua atuação, estrutura e faturamento. Após são descritas as aplicações da análise CVL pelas empresas pesquisadas, além de outras técnicas utilizadas e os planos com relação à melhoria do processo de decisão baseado em custos. Todas as empresas, por uma questão de confidencialidade, estão identificadas por número (1, 2 e 3$)$.

\subsection{Empresa 1 - setor alimentício}

De origem brasileira e com capital fechado, a Empresa 1 possui uma unidade instalada no Rio Grande do Sul e outras duas em fase de construção na região Centro-Oeste. Atua há mais de 20 anos com suas atividades baseadas na industrialização e comercialização de produtos para frigoríficos. Atualmente, suas operações comerciais são voltadas $86 \%$ para o mercado interno e $14 \%$ para o mercado externo, sendo o faturamento bruto anual situado em aproximadamente R\$ 150 milhões, registrados no ano de 2009. É considerada uma empresa de médio-grande porte, de acordo com o BNDES (2010).

Tem como destaque a estratégia competitiva predominante em diferenciação, atuando em um mercado com baixa concorrência. A entrevista foi realizada com um funcionário graduado e mestre em Ciências Contábeis, que atua como controller e consultor da empresa. 


\subsubsection{Estruturação da área e das informações de custos na empresa}

Nos primeiros anos de atividade existiam apenas controles gerenciais referentes a cálculos de custos individuais de cada produto e formação do preço de venda dos produtos, com o uso de planilhas de Excel. No entanto, cabe salientar que naquele tempo existiam apenas dois tipos de produtos fabricados, o que facilitava e até possibilitava os controles apenas por planilhas. Com o crescimento das atividades, a empresa identificou a necessidade de buscar softwares específicos para auxiliar na gestão administrativa. Entretanto, a área de custos foi efetivamente implantada em julho de 2009, com o apoio de consultorias e de um novo sistema de informação.

Desde então, as informações obtidas pela área de custos contribuem para: (a) o desenvolvimento, execução e análise de planejamentos da organização; (b) o gerenciamento de projetos e planos de ação a serem ou já desenvolvidos; (c) o controle das performances de cada produto, atividade ou unidade de negócio; (d) o levantamento de custos das formulações técnicas de cada produto fabricado pela empresa, o que torna o processo de criação de novos produtos ainda mais ágil; (e) o desempenho da empresa por meio do monitoramento de indicadores estratégicos e operacionais criados pela empresa; (f) a análise financeira e comercial da empresa; (g) a tabulação de gráficos comparativos conforme estipulado pela empresa, ou seja, as oscilações de um mesmo produto em determinado período de tempo tanto quanto a comparação de diferentes produtos em determinado período.

\subsubsection{Aplicação da análise CVL}

A empresa, atualmente, não utiliza as práticas de análise CVL para o controle gerencial de suas operações. Dentre os elementos da análise, a margem de contribuição é calculada apenas no total por unidade de negócio, sem ser identificada por produto. A organização justifica a inexistência desta técnica, devido às seguintes dificuldades encontradas: (a) o cálculo do ponto de equilíbrio por produto; (b) saber se o rateio dos custos realizado está correto e não distorce as informações dos produtos; (c) com as diversas oscilações de capitalização e descapitalização da empresa durante o ano; (d) dificuldade em saber qual unidade de negócio ou qual produto deve receber aumento de receita.

No entanto, apesar dos diversos anseios com a técnica, observou-se que a empresa tem como objetivo melhorar a compreensão sobre as ferramentas da análise CVL e utilizá-las para que auxiliem no processo de tomada de decisão.

Os entrevistados afirmaram conhecer a expressividade do assunto na literatura, na qual é enfatizado como sendo um importante instrumento auxiliar para decisões, no entanto, justificaram que na prática a decisão sobre a utilização de uma ferramenta deve ser bem estudada antes da sua implantação. Este é o atual estágio da empresa.

\subsubsection{Considerações finais}

Apesar de a empresa 1 não utilizar a analise CVL, ela utiliza o método da Contabilidade dos Ganhos, muito semelhante ao método de custeio variável, como uma ferramenta gerencial de apoio às decisões. Com o cálculo da margem de ganho, a organização identifica o resultado 
econômico por cliente, representante, mercado, unidade de negócio, produto, entre outros. Nesse método são levados em consideração somente os custos variáveis totalmente identificados aos produtos.

Os entrevistados destacaram que a restrição à análise CVL deve-se ao fato de alocar os custos fixos aos produtos, podendo levar a decisões equivocadas - aqui parece haver uma questão técnica a ser esclarecida, referente à alocação dos custos fixos na análise CVL, o que contraria o conceito básico do custeio variável. O entrevistado acrescentou que para cálculo da margem de ganho excluem-se das receitas operacionais as peculiaridades (tributos, comissões e fretes) de cada um dos mercados onde são comercializados os produtos, para que se obtenha a informação sobre o potencial de cada produto ao identificar, de fato, qual possui o melhor preço de venda. A margem de ganho possibilita, também, a comparação do retorno de cada produto.

Diante disso, a empresa por enquanto utiliza esta técnica para buscar informações gerenciais, no entanto, como a área de custos ainda é recente, existem diversos projetos sendo estudados e implantados na organização, tais como: cálculo do preço de transferência interna, custo padrão e custo meta e, como já comentado, as ferramentas da análise CVL.

\subsection{Empresa 2 - setor químico}

A Empresa 2 atua no segmento químico, fornecendo adesivos para vários tipos de aplicação e clientes variados. Constituída em 1948, a empresa tem seu capital fechado, com uma receita líquida acima de $\mathrm{R} \$ 300$ milhões no ano, base 2009, sendo considerada uma empresa de grande porte, de acordo com o BNDES (2010). Possui forte atuação em diversos países da América Latina e em outras localidades do Brasil.

Caracterizada por atuar em um mercado de forte concorrência, mantém o foco em diferenciar os seus produtos, agregando novas características e qualidade, mas sem deixar de manter o baixo custo para se manter competitiva. Possui um programa forte de investimentos em pesquisa e desenvolvimento, como forma de manter a diferenciação no mercado em que atua.

\subsubsection{Estruturação da área e das informações de custos na empresa}

A área de Controladoria da organização tem como um dos objetivos a análise das informações gerenciais, incluindo as informações de custos, e servir de suporte ao processo decisório.

A área é formada por um Controller, o qual foi entrevistado para este estudo, e mais 5 funcionários. Há, também, a área da Contabilidade, segregada desta, que trata dos custos para fins fiscais. A empresa conta com um sistema integrado de informações que fornece os dados de custos importantes para a gestão.

\subsubsection{Aplicação da análise CVL}

Identificou-se a aplicação da margem de contribuição, margem de segurança e avaliação da alavancagem operacional na empresa. Mensalmente, junto com a diretoria, um grupo de 
executivos representantes das áreas de suprimentos, financeiro, comercial, custos e planejamento e controle da produção, se reúnem com a finalidade de analisar lista de preço e pedidos a serem atendidos. Nessas discussões são utilizados os resultados das ferramentas da análise CVL, a fim de identificar os produtos com maior margem, análise sobre as possibilidades de alteração de preços de venda, verificação sobre a margem de segurança por produto e total, analisar o aceite ou não de pedidos especiais, além do acompanhamento sobre a utilização dos custos fixos com relação ao volume vendido.

Apesar da situação da empresa ser estável em relação à demanda e produção, em ocasiões especiais nas quais mudanças no ambiente são evidenciadas, tem-se também a utilização do ponto de equilíbrio. Exemplo de tais mudanças é a negociação de pedidos especiais que demandam novas estruturas produtivas,assim como a análise de situações que requerem o desligamento de uma máquina relevante no processo produtivo ou mesmo a aquisição de uma máquina nova. Há aqui a preocupação com a geração de custos fixos.

\subsubsection{Considerações finais}

A empresa utiliza-se das ferramentas da análise CVL, sendo a margem de contribuição, margem de segurança operacional e a análise da alavancagem operacional utilizadas na rotina da gestão de custos, e o ponto de equilíbrio utilizado em situações especiais.

Pode-se verificar que a Empresa 2 possui atuação em um mercado competitivo, levando-a a gestão controlada dos custos. Realça o fato de ser ela uma empresa com foco na diferenciação e fazer a gestão por meio dos resultados das análises custo-volume-lucro. É a confirmação da importância de que, mesmo investindo em diferenciação, há a preocupação para existência uma estrutura de baixo custo a fim de assegurar a competitividade.

\subsection{Empresa 3 - setor siderúrgico}

A empresa, de origem brasileira, foi constituída há mais de 50 anos. Atualmente com capital aberto, atua no mercado brasileiro e tem presença em mercados internacionais. Possui sua produção voltada para o segmento do aço e atende clientes de diversos setores da indústria, sendo seu faturamento bruto acima de R $\$ 5$ bilhões, no ano de 2009. É considerada com uma empresa de grande porte, conforme circular do BNDES (2010). A organização atua em um mercado bastante competitivo com foco em baixo custo.

Possui uma estrutura organizacional dividida em unidades de negócio visando facilitar a gestão das suas operações, sendo essas divisões caracterizadas por sua posição geográfica e produtos fabricados.

A entrevista foi realizada com dois executivos da área de custos de divisões diferentes, um graduado em Ciências Contábeis e outro em Administração de Empresas.

\subsubsection{Estruturação da área e das informações de custos na empresa}

Nesta pesquisa estão abordadas as técnicas de gestão de custos aplicadas por duas divisões da empresa localizadas no Brasil. Essas divisões possuem uma área de custos específica 
ao controle da sua operação, além de uma área corporativa responsável pela análise geral das variações de custos de todas as unidades.

A empresa possui sistemas integrados que possibilita a geração de informações de custos para fins fiscais e, também, para fins gerenciais, com o objetivo principal de apoiar o processo decisório.

Cada unidade organizacional é responsável pela geração de relatórios gerenciais sobre os custos de suas operações, apesar da subordinação a uma gestão de controladoria corporativa que estabelece alguns procedimentos padrões.

\subsubsection{Aplicação da análise CVL}

Em uma das divisões, cujo foco principal está na exportação, utiliza-se a margem de contribuição com intensidade, desde 1985, principalmente para definição do preço de venda.

A análise da margem é realizada por família de produto, e não individualmente por produto, devido à grande variedade do mix, tornando inviável a análise individual. Além disso, é utilizada para a definição do mix ótimo de produção e para auxiliar no processo de tomada de decisão quando há um fator limitante da produção, ou seja, quando a demanda é maior que a capacidade operativa. Atualmente, devido à maior complexidade da capacidade produtiva instalada, a empresa está iniciando o desenvolvimento de um sistema informatizado que auxilie nessas decisões mediante uma mais estruturada e específica geração de informações.

A área de custos também possui um papel importante de auxiliar na área de vendas, principalmente quando há necessidade de decidir sobre a aceitação de pedidos especiais que abrangem grandes volumes. A margem de contribuição é novamente fator decisivo e analisado nesses casos.

Com relação à outra divisão analisada, cujo foco está centrado no mercado interno, identifica-se que não é utilizada nenhuma ferramenta da análise CVL. Conforme esclarecido pelo entrevistado, por ser uma operação voltada para o mercado interno, onde a concorrência é menos agressiva que o mercado internacional, historicamente não há uma preocupação para utilização destas ferramentas. Entretanto, o conceito dos gestores sobre a aplicabilidade da análise está mudando, devido à facilidade de entrada para novos concorrentes no Brasil, caracterizando aumento da concorrência. Assim, já é possível notar iniciativas para implantação das ferramentas da análise CVL, com um foco inicial para a utilização da margem de contribuição.

Adicionalmente, foi verificado que o ponto de equilíbrio não é utilizado no dia-a-dia das divisões analisadas. Entretanto, área de custos corporativa, em situações especiais, o aplica em decisões estratégicas, como por exemplo, quando da necessidade de redução ou aumento de custos fixos ou para decisões a respeito do fechamento ou abertura de novas unidades.

\subsubsection{Considerações finais}

Apesar de a Empresa 3 não utilizar as ferramentas da análise CVL na sua totalidade é percebida a aplicação da margem de contribuição em uma das divisões. Na outra divisão, identifica-se apenas a aplicação da margem total, sendo que para seu cálculo são agregados 
ao produto os custos fixos e variáveis existentes. Há projetos futuros de melhoria dos sistemas utilizados pela organização e consequente utilização futura da margem de contribuição.

A empresa, além das ferramentas citadas, realiza reuniões mensais para a gestão dos seus custos, incluindo todas as divisões, nas quais são estudadas as variações sobre preços de venda, volume e consumo, e suas relações com os custos fixos e variáveis. Além disso, há uma análise sobre o percentual de utilização dos custos fixos versus o volume de produção. Esses elementos são acompanhados e comparados com metas definidas no início do ano, com tratamento para as diferenças tratadas.

Pode-se constatar também uma diferença entre as práticas adotadas com relação à análise de preços de venda, utilização dos fatores de produção e aceitação de pedidos de venda nas divisões de uma mesma empresa. Esse fato deve-se a diferente realidade de disputa de mercado a que cada divisão é exposta, sendo este mesmo o motivo que leva às organizações a realizar a divisionalização.

Ainda que a nível corporativo, situações especiais e no nível estratégico tem ensejado a adoção da técnica do ponto de equilíbrio.

\subsection{Análise cruzada dos casos estudados (Cross-case analysis)}

Citou-se, na seção de Estudos Relacionados deste artigo, que existe uma expressividade do tema Análise CVL na literatura de livros e que nos congressos nacionais não se identifica a mesma relevância do tema. Inclusive, por meio da Tabela 1, é possível concluir que a presença do tema é muito baixa nesses eventos científicos.

Nos três casos estudados, não é possível concluir sobre homogeneidade de aplicação das ferramentas. Os cenários de utilização da ferramenta são diferentes em cada um dos casos estudados. A Empresa 1 não utiliza as ferramentas e, apesar de estarem estudando a sua aplicação, possuem algumas restrições com relação a mesma. Utilizam outras técnicas para gestão de custos e tomada de decisão. A Empresa 2 utiliza todos os conceitos da análise CVL e percebe os benefícios das informações geradas através das ferramentas. Já a Empresa 3 utiliza em parte, somente a margem de contribuição em uma das suas divisões. Além de utilizar o ponto de equilíbrio em situações especiais.

Apesar dos casos estudados basearem-se em empresas de grande porte, não é este o fator que parece caracterizar a utilização da análise CVL. No entanto, ao identificar as características das empresas e os cenários de cada uma, é possível estabelecer uma relação com o seu ambiente externo, principalmente com o fator de concorrência nos respectivos segmentos de atuação.

A Empresa 1 atua em um segmento sem competição, focada na diferenciação dos seus produtos. Devido a esse ambiente menos acirrado, pode-se concluir que a preocupação com o acompanhamento dos custos é menos relevante. Sendo a análise CVL uma ferramenta de suporte à tomada de decisão, quando da ocorrência de mudanças nos volumes, custos e preços, o fato de estar atuando em um segmento menos competitivo e sem muitas variações possibilita que a empresa atue sem a utilização dessas ferramentas.

Com a Empresa 2 a situação é oposta, visto que sua atuação ocorre num ambiente competitivo e, ainda, com o agravante de que ela precisa manter a diferenciação dos seus 
produtos com relação aos seus concorrentes. Assim, evidencia-se a aplicação da análise sobre as relações custo-volume-lucro, como suporte à tomada de decisões, utilizadas mensalmente nas reuniões gerenciais e nas decisões mais pontuais.

Já a Empresa 3, apresenta diferentes cenários nas suas divisões. Assim, aplica a margem de contribuição na divisão que tem maior exposição à concorrência e não aplica naquela que participa em um ambiente menos acirrado. Por apresentar uma estratégia de baixo custo, utilizase de ferramentas de gestão de custos e possui procedimentos periódicos de controle. Apesar de não utilizar a análise CVL, foi mencionado o interesse em iniciar a aplicação das técnicas.

Além da relação com a estratégia competitiva dos casos estudados, pode-se concluir também que todas indicaram conhecer as técnicas e haver interesse na implantação para àquelas que não utilizam e para melhoria naquelas que já aplicam.

\section{CONCLUSÃO}

Com o estudo, pode-se constatar que a análise custo-volume-lucro, um tema de tradicional abordagem na literatura existente, tem aplicação apenas relativa nas empresas pesquisadas neste artigo. Mesmo as pesquisas desenvolvidas em âmbito nacional e publicadas em anais de congressos, meio no qual são discutidas novas idéias sobre teoria e prática, verificou-se que a realidade sobre o tema caracteriza-se por uma baixa representatividade frente aos demais assuntos apresentados.

Embora não exista base para generalizações, o estudo dos casos analisados possibilita concluir que aparentemente não há uma aplicação representativa do tema na prática. Em apenas um dos casos estudados, pode-se dizer que a análise CVL é utilizada em sua totalidade, pois considera todos os instrumentos disponibilizados: margem de contribuição, margem de segurança, alavancagem operacional e ponto de equilíbrio.

Pelo conteúdo apresentado nos casos estudados percebe-se que a adoção da prática de gestão analisada é dependente do nível de concorrência e da ameaça de perda de competitividade percebida pelos gestores nos casos estudados. Isso chama atenção na atualidade da gestão empresarial, cuja busca pela eficiência, eficácia e eliminação de desperdício é uma discussão recorrente. Ou seja, independente das condições concorrenciais de momento o investimento no amadurecimento da gestão deveria ser uma constante, uma contínua busca de melhorias.

Ademais, pode-se identificar que os desenvolvimentos teóricos enfatizados pela literatura, sejam eles tradicionais como a análise CVL, explorada neste artigo, ou as mais contemporâneas, como por exemplo, as práticas da Gestão Estratégica de Custos (GEC), não têm sido reconhecidas e implantadas na prática empresarial, tal como preconiza a literatura. Autores como Cinquini e Tenucci (2006), Quesado e Rodrigues (2007) e Reckziegel, Souza e Diehl (2007) identificaram em seus estudos a discrepância entre a realidade das organizações e as práticas enfatizadas na literatura, no que diz respeito à GEC.

Importante salientar que o estudo de casos múltiplos, realizado neste artigo, não pode ser considerado como uma expressão da realidade das demais empresas brasileiras, as quais podem utilizar o método para apoio gerencial. Diante disso, são recomendados como estudos futuros a verificação da aplicabilidade da análise CVL na prática empresarial com a realização 
de pesquisas survey, em uma amostra de coleta de dados de maior abrangência. Para tanto, estudos quantitativos parecem mais adequados à explicação de tendências sobre a utilização das técnicas relacionadas à análise CVL, sejam essas tendências por segmentos da indústria, porte das empresas, ambiente competitivo, entre outros atributos.

\section{REFERÊNCIAS}

ANDRIOLI, Rosane de Fátima. Proposta de modelo flexível para apoio à decisão de externalização: uma aplicação em logística de transporte. (Dissertação) - Mestrado em Ciências Contábeis da Universidade do Vale do Rio dos Sinos - UNISINOS. São Leopoldo, 2009.

ABC - ASSOCIAÇÃO BRASILEIRA DE CUSTOS. Congresso Brasileiro de Custos. Disponível em: $<$ http://www.abcustos.org.br/congresso/view?ID_CONGRESSO=21 > Acesso em: 15 de jun 2010.

ANPAD - ASSOCIAÇÃO NACIONAL DE PÓS-GRADUAÇÃO E PESQUISA EM ADMINISTRAÇÃO. Encontros da ANPAD. Disponível em: < http://www.anpad.org.br/ eventos.php? cod_evento=1>. Acesso em: 03 jun. 2010.

ATKINSON, Anthony; BANKER, Ravij D.; KAPLAN, Robert S.; YOUNG, S. Mark. Contabilidade Gerencial. 2.ed. São Paulo: Atlas, 2008.

BELKAOUI, A. Quantitative Models in Accounting. Quorum Books, 1987.

BNDES - BANCO NACIONAL DE DESENVOLVIMENTO ECONÔMICO E SOCIAL. Carta Circular $\mathbf{N}^{\mathbf{0}} \mathbf{1 0} / \mathbf{2 0 1 0}$. Alterações das normas relativas ao porte das beneficiárias. Março, 2010.

BRUNI, Adriano Leal; FAMÁ, Rubens. Gestão de Custos e Formação de Preços. 5.ed. São Paulo: Atlas, 2008.

BUSAN, Gabriela; DINA, Ionela Claudia. Using cost-volume-profit analysis in decision making. Congresso da University Petrosani Economics. Anais... Romênia, v. 9, n. 3, p.103106, 2009.

CINQUINI, Lino e TENUCCI, Andrea. Strategic management accounting: exploring distinctive features and links with strategy. 2006. Disponível em: http://mpra.ub.uni.muenchen. de/212/. Acesso em: 20 ago 2010.

CHEUNG, Joseph K.; HEANEY, John. A contingent-claim integration of cost-volume-profit analysis with capital budgeting. Contemporary Accounting Research, v. 6, n. 2, p. 738-760, 1990.

DALMONECH, L. F.; MARTINEZ, Antonio Lopo; VIANA, Antonio; FERREIRA, Carlos José Souza. Limitações da análise tradicional de custo-volume-lucro: repensando as hipóteses simplificadoras do modelo. Congresso Brasileiro de Custos, 10. Anais... Guarapari: ES, 2003, p.1-18. 
DUBOIS, Alexy; KULPA, Luciana; SOUZA, Luiz Eurico de. Gestão de custos e formação de preços: conceitos, modelos e instrumentos: abordagem do capital de giro e da margem de competitividade. 3.ed. São Paulo: Atlas, 2009.

EISENHARDT, K. M. Building theories from case study research academy of management. The Academy of Management Review, v. 14, n. 4, p. 532-550, Out 1989.

FREZATTI, Fábio; GUERREIRO, Reinaldo; AGUIAR, Andson, Braga de. Diferenciações entre a Contabilidade Financeira e a Contabilidade Gerencial: Uma Pesquisa Empírica a partir de Pesquisadores de Vários Países. Revista de Contabilidade \& Finanças - USP, n. 44, p. 9-22. Mai/Ago 2006.

GARRISON, Ray H.; HOREEN, Eric W. Contabilidade Gerencial. 9.ed. Rio de Janeiro: LTC, 2001.

GIL, Antônio Carlos. Métodos e técnicas de pesquisa social. 5.ed. São Paulo: Atlas, 1999.

GITMAN, Lawrence J. Princípios de Administração Financeira. 10.ed. São Paulo: Pearson Addison Wesley, 2004.

GUIDRY, Flora; HORRIGAN, James O.; CRAYCRAFT, Cathy. CVP Analysis: A New Look. Journal of Management Issues, v. 10, n. 1, p. 74-85, 1998.

HANSEN, Don R.; MOWEN, Maryanne M. Gestão de custos. São Paulo, Atlas, 2001.

HORNGREN, George T.; FOSTER, George; DATAR, Srikant M. Contabilidade de custos: uma abordagem gerencial. 11.ed. São Paulo: Prentice Hall, 2004.

IUDÍCIBUS, Sérgio. A gestão estratégica de custos e sua interface com a contabilidade gerencial e teoria da contabilidade. CFC, RBC, n. 100, p. 30-31, jul/ago 1996.

JAEDICKE, R.K.; ROBICHEK, A. A. Cost-volume-profit analysis under conditions of uncertainty. The Accounting Review, p. 917-926, out 1964.

LAKATOS, Eva Maria; MARCONI, Marina de Andrade. Técnicas de pesquisa: planejamento e execução de pesquisas, amostragens e técnicas de pesquisas, elaboração, análise e interpretação de dados. 4.ed. São Paulo: Atlas, 1999.

MAHER, Michel. Contabilidade de Custos: criando valor para a administração. São Paulo: Atlas, 2001.

MARTINS, Eliseu. Contabilidade de Custos. 9.ed. São Paulo: Atlas, 2009.

MORAES, Livia C.; WERNKE, Rodney. Análise do custo/volume/lucro aplicada ao comércio de pescados. Revista de Administração Contemporânea, v. 1, n. 6, p. 81-101, Jul/Dez 2006.

QUESADO, Patrícia R.; RODRIGUES, Lúcia L. A gestão estratégica de custos em grandes

empresas portuguesas. Revista Ibero Americana de Contabilidad de Gestion, v.1, n.10, p.121-143, 2007. 
RAYBURN, Letricia G. Cost accouting: using a cost management Approach. 6.ed. Boston: Irwin MacGraw-Hill, 1996.

RECKZIEGEL, V.; SOUZA, M.A.; DIEHL, C.A. Práticas de gestão adotadas por empresas estabelecidas nas Regiões Noroeste e Oeste do Paraná. RBGN, v.9, n.23, p.14-27, 2007.

SAHA, S; CORLEY, K. Building Better Theory by Bridging the Quatitative-Qualitative Divide. Journal of Management Studies, v. 43, n. 8, p;1821-1835, December 2006.

SOUZA, Marcos Antônio; DIEHL, Carlos Alberto. Gestão de Custos: uma abordagem integrada entre contabilidade, engenharia e administração. São Paulo: Atlas, 2009.

SOUZA, Marcos Antônio; LISBOA, Lázaro Plácido; ROCHA, Wellington. Práticas de contabilidade gerencial adotadas por subsidiárias brasileiras de empresas multinacionais. Revista de Contabilidade \& Finanças - USP, n. 32, p. 40-57, Maio/Ago 2003.

USP - UNIVERSIDADE DE SÃO PAULO. Congresso USP de Controladoria e Contabilidade - Lista de trabalhos selecionados. Disponível em: <http://www.congressousp.fipecafi.org/ lista-trabalhos-aprovados.asp>. Acesso em: 03 jun. 2010.

VENTURA, Magda Maria. O estudo de caso como modalidade de pesquisa. Revista SOCERJ, v. 20, n. 5, p. 383-386. Setembro/Outubro, 2007.

WARREN, Carl S.; REEVE, James M.; FEES, Philip E. Contabilidade gerencial. 2.ed. São Paulo: Pioneira Thomson Learning, 2001.

WERNKE, Rodney. Gestão de custos: uma abordagem prática. 2.ed. São Paulo: Atlas, 2004.

YIN, Robert K. Estudo de caso: planejamento e métodos. 2.ed. Porto Alegre: Bookman, 2001.

YUAN, Fong-Ching. The use of a fuzzy logic-based system in cost-volume-profit analysis under uncertainty. Expert Systems with Applications, v. 36, n. 2, p. 1155-1163, Mar 2009.

YUNKER, James A.; YUNKER, Penelope J. Stochastic CVP analysis as a gateway to decisionmaking under uncertainty. Journal of Accounting Education, v. 21, n.4, p. 339-365, 2003. 


\section{ENDEREÇO DE AUTORES:}

\section{Marcos Antonio de Souza}

Universidade do Vale do Rio dos Sinos, Centro de Ciências Econômicas, Área de Conhecimento e Aplicação de Contabilidade, Custos e Finanças.

Av. Unisinos, 950, Cristo Rei

93022-000 - São Leopoldo, RS - Brasil

\section{Carla Schnorr}

Universidade do Vale do Rio dos Sinos, Centro de Ciências Econômicas

Área de Conhecimento e Aplicação de Contabilidade, Custos e Finanças.

Av. Unisinos, 950, Cristo Rei

93022-000 - São Leopoldo, RS - Brasil

\section{Fernanda Baldasso Ferreira}

Universidade do Vale do Rio dos Sinos, Centro de Ciências Econômicas

Área de Conhecimento e Aplicação de Contabilidade, Custos e Finanças.

Av. Unisinos, 950, Cristo Rei

93022-000 - São Leopoldo, RS - Brasil 